\title{
The use of artificial substrate units to improve inventories of cryptic crustacean species on Caribbean coral reefs
}

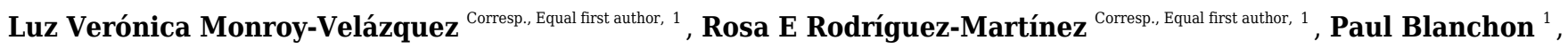 \\ Fernando Alvarez ${ }^{2}$ \\ 1 Instituto de Ciencias del Mar y Limnología, Universidad Nacional Autónoma de México, Puerto Morelos, Quintana Roo, México \\ 2 Colección Nacional de Crustáceos, Instituto de Biología, Universidad Nacional Autónoma de México, Mexico City, Mexico City, México \\ Corresponding Authors: Luz Verónica Monroy-Velázquez, Rosa E Rodríguez-Martínez \\ Email address: plesionika.vmv@gmail.com, rosaer@cmarl.unam.mx
}

Motile cryptofauna inhabiting coral reefs are complex assemblages that utilize the space available among dead coral stands and the surrounding coral rubble substrate. They comprise a group of organisms largely overlooked in biodiversity estimates because they are hard to collect and identify, and their collection causes disturbance that is unsustainable in light of widespread reef degradation. Artificial substrate units (ASUs) provide a better sampling alternative and have the potential to enhance biodiversity estimates. The present study examines the effectiveness of ASUs made with defaunated coral rubble to estimate the diversity of motile cryptic crustaceans in the back-reef zone of the Puerto Morelos Reef National Park, Mexico. Species richness, Simpson's diversity index, Shannon-Wiener index and the composition of assemblages were compared between ASUs and samples from the surrounding coral rubble substrate. A combined total of 2,740 specimens of 178 different species, belonging to five orders of Crustacea (Amphipoda, Cumacea, Isopoda, Tanaidacea and Decapoda) were collected. Species richness was higher in the surrounding coral rubble and Shannon-Wiener and Simpson indexes were higher in ASUs. Species composition differed between methods, with only 71 species being shared among sampling methods. Decapoda was more speciose in ASUs and Peracarids in the surrounding coral rubble. Combining the use of ASUs with surrounding rubble provided a better inventory of motile cryptic crustacean biodiversity, as $65 \%$ of the species were represented by one or two specimens. 
1 The use of artificial substrate units to improve inventories of cryptic crustacean species on 2 Caribbean coral reefs

3

4 Luz Verónica Monroy-Velázquez ${ }^{1}$, Rosa E. Rodríguez-Martínez ${ }^{1}$, Paul Blanchon ${ }^{1}$, Fernando

5 Alvarez $^{2}$

$6{ }^{1}$ Instituto de Ciencias del Mar y Limnología, Universidad Nacional Autónoma de México,

7 Puerto Morelos, Quintana Roo, México.

$8{ }^{2}$ Colección Nacional de Crustáceos, Instituto de Biología, Universidad Nacional Autónoma de 9 México, Mexico City, México.

11 Corresponding authors:

12 Luz Verónica Monroy-Velázquez

13 Email address: plesionika.vmv@gmail.com

Rosa E. Rodríguez-Martínez

Email address: roser@cmarl.unam.mx

ABSTRACT

Motile cryptofauna inhabiting coral reefs are complex assemblages that utilize the space available among dead coral stands and the surrounding coral rubble substrate. They comprise a group of organisms largely overlooked in biodiversity estimates because they are hard to collect and identify, and their collection causes disturbance that is unsustainable in light of widespread reef degradation. Artificial substrate units (ASUs) provide a better sampling alternative and have the potential to enhance biodiversity estimates. The present study examines the effectiveness of ASUs made with defaunated coral rubble to estimate the diversity of motile cryptic crustaceans in the back-reef zone of the Puerto Morelos Reef National Park, Mexico. Species richness, Simpson's diversity index, Shannon-Wiener index and the composition of assemblages were compared between ASUs and samples from the surrounding coral rubble substrate. A combined 
total of 2,740 specimens of 178 different species, belonging to five orders of Crustacea

(Amphipoda, Cumacea, Isopoda, Tanaidacea and Decapoda) were collected. Species richness was higher in the surrounding coral rubble and Shannon-Wiener and Simpson indexes were higher in ASUs. Species composition differed between methods, with only 71 species being shared among sampling methods. Decapoda was more speciose in ASUs and Peracarids in the surrounding coral rubble. Combining the use of ASUs with surrounding rubble provided a better inventory of motile cryptic crustacean biodiversity, as $65 \%$ of the species were represented by one or two specimens.

\section{Keywords}

Coral reefs, Survey methods, Biodiversity, Peracarids, Decapods, Rubble

\section{INTRODUCTION}

Estimating the biodiversity of coral reefs is challenging as many invertebrate species are rare, small, and inhabit microhabitats that are difficult to access. This is especially true of cryptofauna, which are a major component of the biodiversity of coral reefs that are hard to estimate (ReakaKudla, 1997; Small et al., 1998), with the subphylum Crustacea being one of the most abundant and speciose groups. Its representatives occupy cracks, crevices and cavities within the reef, ranging from a few millimeters to several centimeters in diameter, including coral framework, bioerosion galleries, and the interstices between large clasts in deposits of skeletal rubble (Hutchings \& Weate, 1977; Peyrot-Clausade, 1980; Reaka-Kudla, 1997). Skeletal rubble is common on coral reefs that are impacted by tropical cyclones and is generated when storm and hurricane waves destroy live coral stands on the shallow inner shelf, and deposit the fragmented 
52 corals as a layer of coarse rubble covering the shallow reef zones (Blanchon, Jones \&

53 Kalbfleisch, 1997). In Caribbean fringing reefs, coral sand and rubble produced during these

54 events is deposited mainly over the crest and the back-reef causing a retrograde accretion

55 through time (Blanchon et al., 2017).

56 Skeletal rubble deposits are reported to be colonized by cryptic crustaceans in as little as two to

57 four weeks (Takada, Abe \& Shibuno, 2007), as they provide microhabitats, feeding areas, and

58 protection against predation (Moran \& Reaka-Kudla, 1991; Buhl-Mortensen et al., 2009;

59 Humphries, La Peyre \& DeCossas, 2011). Yet cryptic crustaceans inhabiting coral rubble have

60 been largely overlooked in biodiversity estimates because individuals are hard to collect and

61 identify. Furthermore, their collection is commonly destructive and involves disturbance to the

62 collection site, which is incompatible with coral reef health and prohibited in marine protected

63 areas.

Artificial substrate units (ASUs) are fabricated structures that mimic the characteristics of natural habitats (Walker, Schlacher \& Schlacher-Hoenlinger, 2007). Their design can provide high spatial diversity, they are easy to place, recover, and relocate, and can provide a standardized sampling effort, allowing direct comparison between different sites (Chapman, 2002; Takada, Abe \& Shibuno, 2007; Baronio, 2008; Takada et al., 2016). ASUs can also be tracked over time to study recruitment and succession processes (Perkol-Finkel \& Beneyahu, 2005), and the response of biota to environmental gradients or short-term disturbances (Walker, Schlacher \& Schlacher-Hoenlinger, 2007).

Several types of ASUs have been developed to study the biodiversity of hard bottom marine habitats (Plaisance et al., 2011; Enochs et al., 2011; Takada et al., 2016). Artificial Reef Matrix Structures, for example, are ASUs made of affordable materials which are designed to mimic 
75 large head corals (Zimmerman \& Martin, 2004). By contrast, ASUs designed to study motile

76 cryptofauna diversity commonly employ mesh trays filled with defaunated coral rubble, which is

77 reported to have the highest species richness, compared to live or recently dead coral (Enoch \&

78 Mazello, 2012). This type of ASU has been employed on Pacific reefs (Enoch et al., 2011;

79 Takada, Abe \& Shibuno, 2012; Takada et al., 2016), but has been used to a lesser extent in the

80 Caribbean, despite the fact that coral rubble is an abundant substrate and plays an important role

81 in harboring diverse cryptofaunal communities, including fish (Choi \& Ginsburg, 1983; Gischler

82 \& Ginsburg, 1996; Valles et al., 2006). In order to determine their efficiency, however, data

83 derived from their employment needs to be compared with data obtained through other sampling

84 methods.

85 In this study, we evaluate the efficiency of ASUs made with plastic mesh-bags filled with

86 defaunated coral rubble as a means of obtaining the crustacean motile cryptofauna diversity and

87 improve the species inventory in the back-reef zone of a Mexican Caribbean reef, where the

88 diversity of cryptic crustaceans in coral rubble has been reported previously (Monroy-Velázquez,

89 Rodríguez-Martínez \& Alvarez, 2017).

MATERIALS AND METHODS

\section{Study site}

93 The study was carried out in the back-reef zone of the Bonanza reef site $\left(20^{\circ} 57^{\prime} 58^{\prime \prime} \mathrm{N}\right.$,

94 086 48'27" W; Fig. 1A), within the Puerto Morelos Reef National Park, in the Mexican

95 Caribbean. The site is characterized by well-developed back-reef and crest zones, and a reef-

96 front with limited structural relief and only small $(<50 \mathrm{~cm})$ scattered coral colonies (Jordán- 
97 Dahlgren, 1979). Between the reef and the shore, lies a reef lagoon $(\sim 2.5 \mathrm{~km}$ wide $)$ colonized by

98 seagrasses and macroalgae. The back-reef environment at Puerto Morelos is the main zone of active coral growth at present and is dominated by Acropora palmata, Orbicella spp., Pseudodiploria spp., Siderastrea siderea, Agaricia agaricites, and Porites astreoides (CaballeroAragón et al., 2020), whereas the crest zone is dominated by A. palmata and Millepora complanata (Jordán-Dahlgren, 1979). After tropical storms and hurricanes, a large amount of skeletal detritus from these coral species accumulates in the back-reef. Based on historical evidence, 27 hurricanes have passed within $50 \mathrm{~km}$ of the town of Puerto Morelos between 1852 to 2019, with Hurricanes Gilbert (1988) and Wilma (2005) being the most intense (National Hurricane Center, 2020). The site is also under the influence of trade winds, which are interrupted by mild cold fronts for periods of 3-10 days in the winter (Ruiz-Rentería, van Tussenbroek \& Jordán-Dahlgren, 1998). The Yucatan current flows northward along the narrow shelf and, during the trade wind season, its superficial waters are transported into the reef area. Monthly average sea surface temperature ranges from 25.1 to $29.9^{\circ} \mathrm{C}$ (Rodríguez-Martínez et al., 2010).

\section{Artificial substrate unit design}

The artificial substrate unit (ASU) was designed using a plastic tray (50 $\mathrm{cm}$ high by $40 \mathrm{~cm}$ wide) within which was placed a mesh bag (with a $35 \mathrm{~mm}$ mesh) filled with $3 \mathrm{~kg}$ of coral rubble (collected from the beach behind to the study site and dried for five days to ensure that it was uncolonized; Fig. 1). The coral rubble selected was naturally porous and ranged in diameter from 5 to $20 \mathrm{~cm}$ (Fig. 1B). The crate was anchored with a concrete block to prevent its displacement by waves and currents (Fig. 1C); the block holes were open to the surface, allowing the 
120 recruitment of cryptofauna (Fig. 1D). Using scuba, two ASUs were placed on the seafloor of the

121 back-reef zone at a depth of $3 \mathrm{~m}$, in the area where coral rubble accumulates after storms and

122 hurricanes. These ASUs were replaced every two to three months with fresh rubble (May,

123 August, and November of 2013, and January of 2014); this period was selected based on the

124 studies of Takada et al. (2007) and Takada et al. (2008) who showed that a period of 2-4 weeks

125 is sufficient for the establishment of cryptofauna on coral reefs. For retrieval, each ASU was

126 placed into a plastic bag to prevent specimen loss. At the same time, $3 \mathrm{~kg}$ of the same-sized coral

127 rubble was collected in-situ from the area surrounding the ASU with an area no larger than $9 \mathrm{~m}^{2}$

128 (Fig. 1E). Once in the boat, both bagged samples were placed in buckets containing seawater and

129 immediately transported to the laboratory. In total eight samples were obtained from ASUs and

130 eight from coral rubble collected in situ throughout the study. All surveys were conducted under

131 permit DGOPA.00008.080113.0006 granted by SAGARPA (Agriculture, Natural Resources and

132 Fisheries Secretariat) to F. Alvarez.

\section{Laboratory work}

135 In the laboratory, the coral rubble obtained from the ASUs and in situ was placed in separate

136 buckets filled with fresh water to provoke osmotic shock and force organisms out of their

137 cavities. The residue material was sieved through a $0.5 \mathrm{~mm}$ mesh. Organisms were preserved in

$13870 \%$ ethanol and later identified to the lowest possible taxonomic level and counted.

139 Identifications followed Suárez-Morales et al. (2004) for Tanaidacea, Heard, Roccatagliata \&

140 Petrescu (2007) for Cumacea, Kensley \& Schotte (1989) for Isopoda, Thomas (1993) and

141 LeCroy (2000, 2002, 2004, and 2007) for Amphipoda, and Williams (1984) for Decapoda. 


\section{Data analysis}

144 Species diversity obtained using the two sampling methods was assessed using Hill Numbers of

145 the effective number of species (Hill, 1973; Chao et al., 2014), namely species richness $(q=0)$,

146 the exponential of Shannon entropy index, or Shannon diversity $(q=1)$, and the inverse of the

147 Simpson concentration index, or Simpson diversity $(q=2)$. Hill Numbers and curves, and

148 measures of sample coverage, were obtained by means of the package iNEXT in the R

149 environment (Hsieh et al., 2016). Sample coverage is a measure of sample completeness that

150 gives the proportion of the total number of individuals in a community that belong to the species

151 represented in the sample (Hsieh et al., 2016). Subtracting the sample coverage from unity gives

152 the probability that the next individual collected belongs to a species not previously collected in

153 the sample (Hsieh et al., 2016).

154 To compare species composition between methods, non-metric multidimensional scaling

155 (NMDS) ordination was employed, using the metaMDS function (Vegan package), with Bray-

156 Curtis dissimilarity measure and 999 permutations. Assemblage compositions were computed

157 based on presence/absence of species. Differences in composition among methods were tested by

158 a permutational multivariate analysis of variance with 9999 permutations, using the

159 nonparametric ADONIS function of the Vegan package in the R environment (Oksanen et al., 160 2013).

161 The Importance Value Index (IVI) (Curtis \& McIntosh, 1951) was used as a proxy to estimate

162 the relative importance of each taxon within each substrate. The IVI of each taxon is calculated

163 as IVI $=(\mathrm{RA}+\mathrm{RF}) / 2$, where $\mathrm{RA}$ is relative abundance, calculated from the number of individuals

164 per taxon with respect to the number of individuals of all species found in the assemblage, and

165 where RF is relative frequency, estimated as the proportion of surveys where a taxon is present, 
166 normalized to the frequency of all species in the assemblage. All analyses were done in R 3.6.3.

167 (R Core Team, 2016).

168

\section{RESULTS}

170 A total of 2,740 specimens belonging to at least 178 species, encompassing five orders of

171 Crustacea (Amphipoda, Cumacea, Isopoda, Tanaidacea and Decapoda) and 58 families were

172 identified and recorded throughout the study. Of these, 129 taxa were identified to species, 39 to

173 genus and ten to higher taxonomic levels. The taxonomic composition of the samples taken using

174 the two methods is summarized in Supplementary Table 1. Fifty-five species (31\%) were

175 represented by a single specimen and $60(34 \%)$ by two specimens each. Forty percent of the

176 species were shared among methods. Decapoda was the most speciose order, with 57 species,

177 followed by Isopoda $(\mathrm{N}=48)$, Amphipoda $(\mathrm{N}=39)$, Tanaidacea $(\mathrm{N}=18)$ and Cumacea $(\mathrm{N}=$

178 16). Three species of Decapoda represent new records for the Mexican Caribbean (Paguristes

179 hernancortezi, Processa profunda, and Processa riveroi). Other specimens that were rarely

180 observed in samples, and were not included in the data analyses, were crustaceans belonging to

181 the class Ostracoda and to the subclass Copepoda, as well as animals belonging to Mollusca,

182 Polychaeta, and Echinodermata.

183 In total, 868 specimens of crustaceans, consisting of at least 116 species, were obtained from the

184 ASUs, and 1,872 specimens, consisting of at least 133 species, were obtained from coral rubble

185 collected in situ (Table 1). Species richness was not significantly different between methods

186 (confidence intervals overlap; Fig. 2) but the identity of the species differed, showing that both

187 contribute to unique taxa; 45 were exclusive to ASUs and 62 were unique to coral rubble

188 collected in situ. In both methods, over half of the species were represented by one or two 
189 specimens $($ ASUs $=57 \%$; Coral rubble $=52 \%)$. Overall, Decapoda was more speciose in ASUs, 190 while Isopoda, Amphipoda, Tanaidacea and Cumacea were more speciose in coral rubble 191 collected in situ (Table 1). Regarding the number of individuals, Isopoda was the most abundant 192 order in ASUs and Tanaidacea in coral rubble collected in situ; species of the order Cumacea 193 were rare in samples obtained by both methods (Table 1).

194 Shannon and Simpson indexes were significantly higher in ASUs $\left(H^{\prime}=39.4 ; \mathrm{D}=18.2\right)$ than in 195 coral rubble collected in situ $\left(\mathrm{H}^{\prime}=27.3 ; \mathrm{D}=13.5\right)$ (confidence intervals don't overlap; Fig. 2).

196 Rarefaction curves of species richness constructed to estimate the reliability of diversity

197 estimates for both methods (Fig. 3) failed to reach a plateau, indicating that sample size was 198 insufficient to reliably estimate the total number of species and thus diversity measurements 199 for each method are conservative (Fig. 2). Estimates of sample coverage, a measure of sampling 200 completeness, were 0.95 for ASUs, 0.97 for coral rubble collected in situ, and 0.98 when both methods were combined (Fig 3).

The nMDS plot, based on presence/absence data in Figure 4, showed no distinct separation of the cryptic crustacean assemblages in the two methods, as confirmed by the high stress value (0.1704). Assemblages obtained from coral rubble collected from in situ samples at different periods were more similar than samples of rubble in ASUs, nevertheless the samples from both methods overlap for some sampling periods; ASUs samples from the first and last surveys were more similar to coral rubble samples collected in situ than to ASUs samples collected in the second and third surveys (Fig. 4). ADONIS test indicated that the method had a small effect,

209 although it was significant $\left(\mathrm{R}^{2}=0.1142, \mathrm{p}=0.0027\right)$. In ASUs, the dominant species were the tanaidacean Chondrochelia dubia (IVI =9.5\%) and the 
212 isopod Cirolana parva $(\mathrm{IVI}=6.2 \%)$, with other relatively important species being the

213 amphipod Elasmopus rapax (IVI = 3.5\%) and the tanaidacean Apseudes sp. A (IVI = 3.4\%) (Fig.

214 5). In coral rubble collected in situ, the dominant species were the tanaidaceans Apseudes sp. A

215 (IVI = 8.6\%), Paratanais sp. A (IVI =7.9\%), Pseudoleptochelia sp. A (IVI =6.2\%) and

216 Chondrochelia dubia (IVI = 5.2\%) (Fig. 5).

\section{DISCUSSION}

219

220

221

222

223

224

225

226

227

228

229

230

231

232

233

Artificial sampling units (ASUs) made with fresh coral rubble and deployed in different seasons for short periods of time (2-3 months) are an effective method for improving species inventory of motile cryptic crustaceans on Caribbean coral reefs. Using this method we recorded 116 species of this group during the one-year study duration at the Bonanza site, 45 of which were not recorded in the surrounding coral rubble. Nevertheless, the ASUs failed to record 62 species that were unique to the surrounding coral rubble. However, the rarefaction curves of species richness for both methods failed to reach a plateau, indicating that more samples were needed to have a complete inventory. By combining both ASUs and surrounding rubble samples, we recorded a total of 178 species, with $65 \%$ being represented by one or two individuals, and reached a sample coverage of $98 \%$ in our sampling size. The nMDS analyses showed no distinct separation of the cryptic crustacean assemblages obtained by the two methods, as samples obtained from ASUs in the first and last surveys overlapped with those obtained from coral rubble collected in situ. However, ASUs samples from intermediate surveys were dissimilar to all others suggesting that it would take more ASUs to provide estimates of the community structure recorded in coral rubble samples, or that ASUs need to be left in place for longer periods. Further studies are 
234 needed to determine at which point in time, or after how many samples, the two methods would

235 yield similar results.

236 Our results support the finding of other studies which suggest that sampling of coral rubble using

237 different techniques would render a higher taxonomic richness (Costello et al., 2017) and a

238 greater potential for the discovery of new species (Souza, Oliveira \& Almeida, 2012; Paz-Ríos,

239 Simões \& Ardisson, 2013). Our ASUs were more effective in sampling decapods, with 23 out of

240 the 57 species recorded being exclusive to this method, while the surrounding coral rubble was

241 more effective for recording unique species of Amphipoda, Cumacea, Isopoda and Tanaidacea,

242 even though some families of these orders were only sampled by ASUs, including the

243 Amphilochidae and Bateidae, of the order Amphipoda, and the Munnidae, of the order Isopoda.

244 Decapod families exclusively found in ASUs were: Hippolytidae, Paguridae, Pilumnidae,

245 Porcellanidae, Spongicolidae and Thoridae.

246 Differences between sampling methods in motile cryptic crustacean species richness, diversity,

247 and assemblage composition could also be explained by the duration of time that each substrate

248 remained underwater, and thus differences in the composition and coverage of algal turfs.

249 Peracarids like a layer of turf algae and fine sediment particles on which to feed, while decapods

250 were more likely recruiting to ASUs for shelter from predators or could be actively foraging

251 within the ASUs. Coral rubble within ASUs had low algal turf coverage, as it stayed in the water

252 for only a few months $(\leq 3)$. Although biofilms formed by bacteria and microalgae can be

253 formed within hours (Cuba \& Blake, 2018), the composition and coverage of the algal

254 assemblage can change significantly within months (Frike et al., 2011), as opportunistic

255 filamentous species are replaced by more competitive fleshy ones and Cyanobacteria (Wanders,

256 1977; Frike et al., 2011). Given that the pattern of succession of algae can shape their 
257 communities (Connell \& Slatyer, 1977), the absence, or low coverage, of certain algal species

258 could have inhibited the colonization or permanence of some of the cryptic crustacean species in

259 the ASUs. Biofilms, for example, are known to release peptides that induce the settlement of

260 several species of sessile invertebrate larvae (Johnson et al., 1997) and sessile assemblages on

261 coral rubble may later affect the colonization of cryptic motile fauna (Klumpp, McKinnon \&

262 Mundy, 1988; Kramer, Bellwood \& Bellwood, 2012). In the coral rubble collected around the

263 ASUs, the algal-turf cover was higher, increasing habitat heterogeneity and allowing detritus to

264 be trapped (Danovaro \& Fraschetti, 2002). This possibly favored a higher species richness of

265 peracarids, in particular of tanaidaceans, which are typically found in early successional stages

266 (Larsen \& Shimomura, 2008).

267 Despite its apparent permanence in back-reef environments, coral rubble cannot be seen as a

268 static substrate, particularly in shallow reef sites, where it can be periodically reworked by

269 currents and large wave events during storms, hurricanes, and north winds, or disturbed by fish

270 feeding and bioerosion, among other factors, thus becoming periodically available for

271 colonization (Takada, Abe \& Shibuno, 2007). All these factors may drive the distribution and

272 structure of cryptic assemblages (Choi \& Ginsburg, 1983; Meesters et al., 1991) and contribute

273 to the maintenance of high species diversity, by avoiding competitive exclusion and facilitating

274 the colonization of less competitive species (Enochs et al., 2011). A higher peracarid species

275 richness would likely be obtained by increasing the number of ASUs per survey and allowing the

276 artificial substrate to become covered by an algal matrix before deployment.

277 The dominant cryptic crustacean species, as obtained by the IVI, differed between sampling

278 methods. Coral rubble substrates were dominated by tanaids (Apseudes sp., Paratanais sp.,

279 Pseudoleptochelia sp. and Chondrochelia dubia), while in ASUs, C. dubia was co-dominant 
280 with isopod Cirolana parva, and the amphipod Elasmopus rapax: these species were probably 281 opportunistic colonizers of new habitat space. Juveniles and ovigerous females of E. rapax, $C$.

282 and decapods (families Alpheidae and Mithracidae) were observed in ASUs throughout the

283 study. The dominant species in ASUs were previously reported as abundant in coral rubble

284 substrates on the Puerto Morelos reef (Monroy-Velázquez, Rodríguez-Martínez \& Alvarez,

285 2017; Winfield et al., 2017), suggesting that, despite their artificial nature, ASUs were not only

286 colonized by some of the most abundant reef species, but also by rare ones too. More studies are

287 needed to determine if ASUs have an effect on the abundance, life stage, and sizes of the

288 individuals recruited.

289 Our findings show that when assessing the effectiveness of ASUs on coral reefs, or other

290 ecosystems, care should be taken in comparing the experimental results with controls collected

291 simultaneously from the same sample station. Changes in either of these variables can produce

292 significant differences in species composition and abundance that will affect comparisons

293 (Moran \& Reaka-Kudla, 1991; Takada et al., 2007). Sessile encrusting or colony forming species

294 are not expected to be common in ASUs, unless they remain in the water for several months or

295 more (Malella, 2007; Duckworth \& Wolff, 2011). Once a broad survey of the species

296 composition of the local coral rubble has been undertaken, it is then possible to evaluate the

297 effectiveness of ASUs. Our results show that the use of ASUs made with defaunated coral rubble

298 is effective in detecting cryptic and rare motile crustaceans, and can help improve species

299 inventories of this group on Caribbean coral reefs.

300

301 Conclusion 
302

303

304

305

306

307

308

309

310

311

312

313

314

315

316

317

318

319

320

321

322

323

324

325

326

Artificial sampling units (ASUs) made with defaunated coral rubble constitute a valuable tool to study the diversity of motile cryptic crustaceans in Caribbean coral reefs. Our results show that combining data from ASUs with that from surrounding coral rubble gives a more complete inventory of species, as both methods contribute unique species. ASUs gave a better estimate of diversity, whereas the surrounding coral rubble gave a better estimate of species richness. By combining both methods we recorded an assemblage of motile cryptic crustaceans composed of at least 178 species encompassing five orders at a single reef site in one year.

\section{Acknowledgments}

We thank the Instituto de Ciencias del Mar y Limnología, UNAM, in particular Dr. Brigitta van Tussenbroek, for providing the laboratory space. Dive Master E. Rodríguez Soria and H. Palma provided logistic help during field work. The manuscript was greatly improved by the suggestions of Ian Enochs, Robert Toonen and one anonymous reviewer. Optical images of the study site in Fig. 1A are from Google Earth (Map data: SIO, NOAA, U.S. Navy, NGA, GEBCO; Image; Landsat/Copernicus; https:/www.google.com/earth/).

\section{References}

Baronio, M.A., Bucher, D.J. 2008. Artificial crevice habitats to assess the biodiversity of vagile macro-cryptofauna of subtidal rocky reefs. Marine and Freshwater Research, 59: 661-670. . http://doi.org/10.1071/MF07170

Blanchon, P., Jones, B., Kalbfleisch, W. 1997. Anatomy of a fringing reef around Grand Cayman; storm rubble, not coral framework. Journal of Sedimentary Research, 67(1): 1-16. http://doi.org/10.1306/D42684D7-2B26-11D7-8648000102C1865D

Blanchon, P., Richards, S., Bernal, J. P., Cerdeira-Estrada, S., Ibarra, M., Corona-Martínez, L., Martell-Dubois, R. 2017. Retrograde accretion of a Caribbean fringing reef controlled by 
hurricanes and sea-level rise. Frontiers in Earth Science, 5, 78. https://doi.org/10.3389/feart.2017.00078

Buhl-Mortensen, L., Vanreusel, A., Gooday, A.J., Levin, L., Priede, G.I., Gheerardyn, H., King, N., Raes, M. 2009. Biological structures as a source of habitat heterogeneity and biodiversity on the deep ocean margins. Marine Ecology, 31: 21-50. https://doi.org/10.1111/j.14390485.2010.00359.x

Caballero-Aragón, H., Perera-Valderrama, S., Cerdeira-Estrada, S., Martell-Dubois, R., Rosiquede la Cruz, L., Álvarez-Filip, L., ... \& Ressl, R. 2020. Puerto Morelos coral reefs, their current state and classification by a scoring system. Diversity, 12(7): 272.

Chao, A., Gotelli, N.J., Hsieh, T.C., Sander, E.L., Ma, K.H., Colwell, R.K., Ellison, A.M. 2014. Rarefaction and extrapolation with Hill numbers: a framework for sampling and estimation in species diversity studies. Ecological Monographs, 84: 45-67. https://doi.org/10.1890/130133.1

Chapman, M.G. 2002. Early colonization of shallow subtidal boulders in two habitats. Journal of Experimental Marine Biology and Ecology, 275: 95-116. http://doi.org/10.1016/S00220981(02)00134-X

Choi, D.R., Ginsburg, R.N. 1983. Distribution of coelobites (cavity-dwellers) in coral rubble across the Florida Reef Tract. Coral Reefs, 2: 165-172. https://doi.org/10.1007/BF00336723

Connell, J.H., Slatyer, R.O. 1977. Mechanisms of succession in natural communities and their role in community stability and organization. The American Naturalist, 111: 1119-1144. http://doi.org/10.1086/283241

Costello, M.J., Basher, Z., McLeod, L., Assad, I., Claus, S., Vandepitte, L., Yasuhara, M., Gislason, H., Edwards, M., Appeltans, W., Enevoldsen, H., Edgar, G., Miloslavich, P., de Monte, S., Sousa Pinto, I., Obura, D., Bates, A. 2017. Methods for the study of marine biodiversity. p. 129-163. In: Scholes, R.J., Walters, M. (Eds), The GEO handbook on biodiversity observation networks. Springer, Cham. 326 p. ISBN 978-3-319-27288-7

Cuba, T.R., Blake, N.J. 1983. The initial development of a marine fouling assemblage on a natural substrate in a subtropical estuary. Botánica Marina, 26: 259-264. http://doi.org/10.1515/botm.1983.26.6.259

Curtis, J.T., McIntosh, R.P. 1951. An upland forest continuum in the prairie-forest border region of Wisconsin. Ecology, 32(3): 476-496. http://doi.org/10.2307/1931725

Danovaro, D., Fraschetti, S. 2002. Meiofaunal vertical zonation on hard-bottoms: comparison with soft-bottom meiofauna. - Marine Ecology Progress Series, 230:159-169 http://doi.org/10.3354/meps230159

Duckworth, A.R., Wolff, C.W. 2011. Population dynamics and growth of two coral reef sponges on rock and rubble substrates. Journal of Experimental Marine Biology and Ecology, 402: 4955. https://doi.org/10.1016/j.jembe.2011.03.017

Enochs, I.C. 2012. Motile cryptofauna associated with live and dead coral substrates: implications for coral mortality and framework erosion. Marine Biology, 159(4): 709-722. https://doi.org/10.1007/s00227-011-1848-7 
367

368

369

370

371

372

373

374

375

376

377

378

379

380

381

382

383

384

385

386

387

388

389

390

391

392

393

394

395

396

397

398

399

400

401

402

403

404

405

406

Enochs, I.C., Manzello, D.P. 2012. Species richness of motile cryptofauna across a gradient of reef framework erosion. Coral Reefs, 31: 653-661. https://doi.org/10.1007/s00338-012-0886-z

Enochs, I.C., Toth, LT, Brandtneris, V.W., Afflerbach, J.C., Manzello, D.P. 2011. Environmental determinants of motile cryptofauna on an eastern Pacific coral reef. Marine Ecology Progress Series, 438: 105-118. http://doi.org/10.3354/meps09259

Fricke, A., Teichberg, M., Beilfuss, S., Bischof, K. 2011. Succession patterns in algal turf vegetation on a Caribbean coral reef. Botanica Marina, 54(2), 111-126. https://doi.org/10.1515/bot.2011.021

Gischler, E., Ginsburg, R.N. 1996. Cavity dwellers (coelobites) under coral rubble in southern Belize barrier and atoll reefs. Bulletin of Marine Science, 58: 570-589.

Heard, R.W., Roccatagliata D., Petrescu, I. 2007. An illustrated guide to Cumacea (Crustacea: Malacostraca: Peracarida) from Florida coastal and shelf waters to depths of $100 \mathrm{~m}$. State of Florida. Department of environmental protection. Tallahassee, Florida, 175 p.

Hill, M.O. 1973. Diversity and evenness: a unifying notation and its consequences. Ecology, 54, 427-432. https://doi.org/10.2307/1934352

Hsieh, C., Ma, K.H., Chao, A. 2016. iNEXT: an R package for rarefaction and extrapolation of species diversity (Hill numbers). Methods in Ecology and Evolution, 7: 1451-1456. http://doi.org/10.1111/2041-210X.12613

Humphries, A.T., La Peyre, M.K., DeCossas G.A. 2011. The effect of structural complexity, prey density, and "predator-free space'" on prey survivorship at created oyster reef mesocosms. PLoS ONE 6, e28339. http://doi.org/10.1371/journal.pone.0028339

Hutchings, P.A., Weate, P.B. 1977. Distribution and abundance of cryptofauna from Lizard Island, Great Barrier Reef. Marine Research in Indonesia, 17: 99-112.

Johnson, C. R., Lewis, T. E., Nichols, D. S., Degnan, B. M. 1997. Bacterial induction of settlement and metamorphosis in marine invertebrates. In: Proceedings of the 8 th International Coral Reef Symposium, 2: 1219-1228.

Jordán-Dahlgren, E. 1979. Estructura y composición de arrecifes coralinos en la región noreste de la Península de Yucatán, México. Anales del Instituto de Ciencias del Mar y Limnología, Universidad Nacional Autónoma de México, 6: 69-86.

Kensley, B., Schotte, M. 1989. Guide to the marine Isopod crustaceans of the Caribbean. Smithsonian Institution Press, Washington, DC, 308 p.

Klumpp, D.W., McKinnon, A.D., Mundy, C.N. 1988. Motile cryptofauna of a coral reef: abundance, distribution and trophic potential. Marine Ecology Progress Series, 45: 95-1081. http://doi.org/10.3354/meps045095

Kramer, M.J., Bellwood, D.R., Bellwood, O. 2012. Cryptofauna of the epilithic algal matrix on an inshore coral reef, Great Barrier Reef. Coral Reefs, 31: 1007-1015. http://doi.org/10.1007/s00338-012-0924-x

Larsen, K. Shimomura M. 2008. Tanaidacea (Crustacea: Peracarida) from Japan. IV. Shallowwater species from Akajima with notes on the recolonization potential of tanaids. Zootaxa 1678(1678): 1-24. https://www.biotaxa.org/Zootaxa/article/view/zootaxa.1678.1.1 
407

408

409

410

411

412

413

414

415

416

417

418

419

420

421

422

423

424

425

426

427

428

429

430

431

432

433

434

435

436

437

438

439

440

441

442

443

444

445

446

LeCroy, S.E. 2000. An illustrated identification guide to the nearshore marine and estuarine gammaridean Amphipoda of Florida. Volume 1. Families Gammaridae, Hadziidae, Isaeidae, Melitidae and Oedicerotidae. Florida Department of Environmental Protection, Tallahassee. $195 \mathrm{p}$.

LeCroy, S.E. 2002. An illustrated identification guide to the nearshore marine and estuarine gammaridean Amphipoda of Florida. Volume 2. Families Ampeliscidae, Amphilochidae, Ampithoidae, Aoridae, Argissidae and Haustoriidae. Florida Department of Environmental Protection, Tallahassee. $213 \mathrm{p}$.

LeCroy, S.E. 2004. An illustrated identification guide to the nearshore marine and estuarine gammaridean Amphipoda of Florida. Volume 3. Families Bateidae, Biancolinidae, Cheluridae, Colomastigidae, Corophiidae, Cyproideidae and Dexaminidae. Florida Department of Environmental Protection, Tallahassee. 90 p.

LeCroy, S.E. 2007. An Illustrated Identification Guide to the Nearshore Marine and Estuarine Gammaridean Amphipoda of Florida, Volume 4. Families Anamixidae, Eusiridae, Hyalellidae, Hyalidae, Iphimedidae, Ischyroceridae, Lysianassidae, Megaluropidae and Melphidippidae. Florida Department of Environmental Protection, Tallahasse Environmental Protection, Tallahassee. $120 \mathrm{p}$.

Malella, J. 2007. Coral reef encruster communities and carbonate production in cryptic and exposed coral reef habitats along a gradient of terrestrial disturbance. Coral Reefs 26: 775785. http://doi.org/10.1007/s00338-007-0260-8

Meesters, E., Knijn R, Willemsen, P., Pennartz R, Roebers, G., van Soest, R.W.M. 1991. Subrubble communities of Curaçao and Bonaire coral reefs. Coral Reefs, 10:189-197. https://doi.org/10.1007/BF00336773

Monroy-Velázquez, L.V., Rodríguez-Martínez, R.E., Alvarez, F. 2017. Taxonomic richness and abundance of cryptic peracarid crustaceans in the Puerto Morelos Reef National Park, Mexico. PeerJ, 5, e3411. http://doi.org/10.7717/peerj.3411

Moran, D.P., Reaka-Kudla, M.L. 1991. Effects of disturbance: disruption and enhancement of coral reef cryptofaunal populations by hurricanes. Coral Reefs, 9(4): 215-224. http://doi.org/10.1007/BF00290425

National Hurricane Center. 2020. https:/oceanservice.noaa.gov/news/historical-hurricanes/ (access date: 30 april 2020).

Oksanen, J., Blanchet, F.G., Kindt, R., Legendre, P., Minchin, P.R., O’hara, R.B., ... \& Oksanen, M.J. 2013. Package ‘vegan'. Community ecology package, version, 2(9), 1-295. https://cran.rproject.org/web/packages/vegan/vegan.pdf

Paz-Ríos, C.E., Simões, N., Ardisson, P.L. 2013. Intertidal and shallow water amphipods (Amphipoda: Gammaridea and Corophiidea) from Isla Pérez, Alacranes reef, southern Gulf of Mexico. Nauplius, 21(2): 179-194. http://doi.org/10.1590/S0104-64972013000200005

Perkol-Finkel, S., Benayahu, Y. 2005. Recruitment of benthic organisms onto a planned artificial reef: shifts in community structure one decade post-deployment. Marine Environment Research, 59: 79-99. http://doi.org/10.1016/j.marenvres.2004.03.122 
447

448

449

450

451

452

453

454

455

456

457

458

459

460

461

462

463

464

465

466

467

468

469

470

471

472

473

474

475

476

477

478

479

480

481

482

483

484

485

Peyrot-Clausade, M. 1980. Motile cryptofauna of Tuléar reef flats. Marine Biology, 59: 43-47. http://doi.org/10.1007/BF00396981

Plaisance, L., Caley, M.J., Brainard, R.E., Knowlton, N. 2011. The diversity of coral reefs: what are we missing? PLoS One, 6(10): e25026. https://doi.org/10.1371/journal.pone.0025026

Reaka-Kudla, M.L. 1997. The global biodiversity of coral reefs: a comparison with rain forests. p. 83-108. In: Biodiversity II: Understanding and Protecting our Biological Resources, Reaka-Kudla, M.L., Wilson, D.E., Wilson, E.O. (Eds.). Joseph Henry Press, Washington D.C., 549 p.

Rodríguez-Martínez, R.E., Ruíz-Rentería, F., van Tussenbroek, B., Barba-Santos, G., EscalanteMancera, E., Jordán-Garza, G., Jordán-Dahlgren, E. 2010. Environmental state and tendencies of the Puerto Morelos CARICOMP site, Mexico. Revista de Biología Tropical, 58(3): 23-43. ISSN 0034-7744

Ruiz-Rentería, F., van Tussenbroek, B.I., Jordán-Dahlgren, E. 1999. Puerto Morelos, Quintana Roo, México. p. 57-66. In: Caribbean Coral Reef, seagrass and mangrove sites. Kjerve B (Ed.), UNESCO, Paris, $347 \mathrm{p}$.

Small, A.E., Adey, W.H., Spoon, D. 1998. Are current estimates of coral reef biodiversity too low? The view through the window of a microcosm. Atoll Research Bulletin, 458: 1-20.

Suárez-Morales, E., Heard, R., García-Madrigal, M., Oliva, J., Escobar, E. 2004. Catálogo de los tanaidáceos (Crustacea: Peracarida) del Caribe Mexicano, CONACYT/SEMARNAT/ECOSUR, México. $121 \mathrm{p}$.

Takada, Y., Abe, O., Shibuno, T. 2007. Colonization patterns of mobile cryptic animals into interstices of coral rubble. Marine Ecology Progress Series, 343: 35-44.

http://doi.org/10.3354/meps06935

Takada, Y., Abe, O., Shibuno, T. 2012. Variations in cryptic assemblages in coral-rubble interstices at a reef slope in Ishigaki Island, Japan. Fisheries Science, 78(1): 91-98. https://doi.org/10.1007/s12562-011-0437-5

Takada, Y., Abe, O, Hashimoto, K., Shibuno, T. 2016. Colonization of coral rubble by motile cryptic animals: Differences between contiguous versus raised substrates from the bottom. Journal of Experimental Marine Biology and Ecology, 475: 62-72. http://doi.org/10.1016/j.jembe.2015.11.007.

Thomas, J.D. 1993. Identification manual for marine Amphipoda (Gammaridea): I. Common coral reef and rocky bottom amphipods of South Florida. Florida Department of Environmental Protection, Tallahassee, Florida. 83 p.

Valles, H., Kramer, D.L., Hunte, W. 2006. A standard unit to monitoring recruitment of fishes to coral reef rubble. Journal of Experimental Marine Biology and Ecology, 336: 171-183.

Walker, S.J., Schlacher, T.A., Schlacher-Hoenlinger, M.A. 2007. Spatial heterogeneity of epibenthos on artificial reefs: fouling communities in the early stages of colonization on an East Australian shipwreck. Marine Ecology, 28(4): 435-445. http://doi.org/10.1111/j.14390485.2007.00193.x 
486

487

488

489

490

491

492

493

494

495

496

497

Wanders, J.B.W. 1977. The role of benthic algae in the shallow reef of Curacao (Netherlands Antilles) III: The significance of grazing. Aquatic Botany, 3: 357-390. http://doi.org/10.1016/0304-3770(77)90040-7

Williams, A.B. 1984. Shrimps, lobsters, and crabs of the Atlantic coast of the United States, Maine to Florida. Smithsonian Institution Press, Washington, D.C., 550 p.

Winfield, I., Abarca-Ávila, M., Ortíz, M., Cházaro-Olvera, S., Lozano-Aburto, M.A. 2017. Biodiversidad de los tanaidáceos (Crustacea: Peracarida: Tanaidacea) del Parque Nacional Arrecife Puerto Morelos, Quintana Roo, México. Revista Mexicana de Biodiversidad, 88: 572-578. http://doi.org/10.1016/rmb.2017.07.006

Zimmerman, T.L., Martin, J.W. 2004. Artificial Reef Matrix Structures (Arms): An Inexpensive and Effective Method for Collecting Coral Reef-Associated Invertebrates. Gulf and Caribbean Research 16 (1): 59-64. https://doi.org/10.18785/gcr.1601.08 


\section{Figure 1}

Study area and method

Study area in the northeastern Caribbean coast of the Yucatan Peninsula: (A) Google Earth image showing the location of Bonanza reef site; (B) Coral rubble collected from the beach; (C) Artificial substrate unit placed inside a vented plastic crane in the back-reef at $\sim 3 \mathrm{~m}$ deep; (D) Artificial substrate unit anchored to the seafloor with a concrete block; (E) Scattered coral rubble in the back-reef zone. Map data: SIO, NOAA, U.S. Navy, NGA, GEBCO; Image; Landsat/Copernicus. 


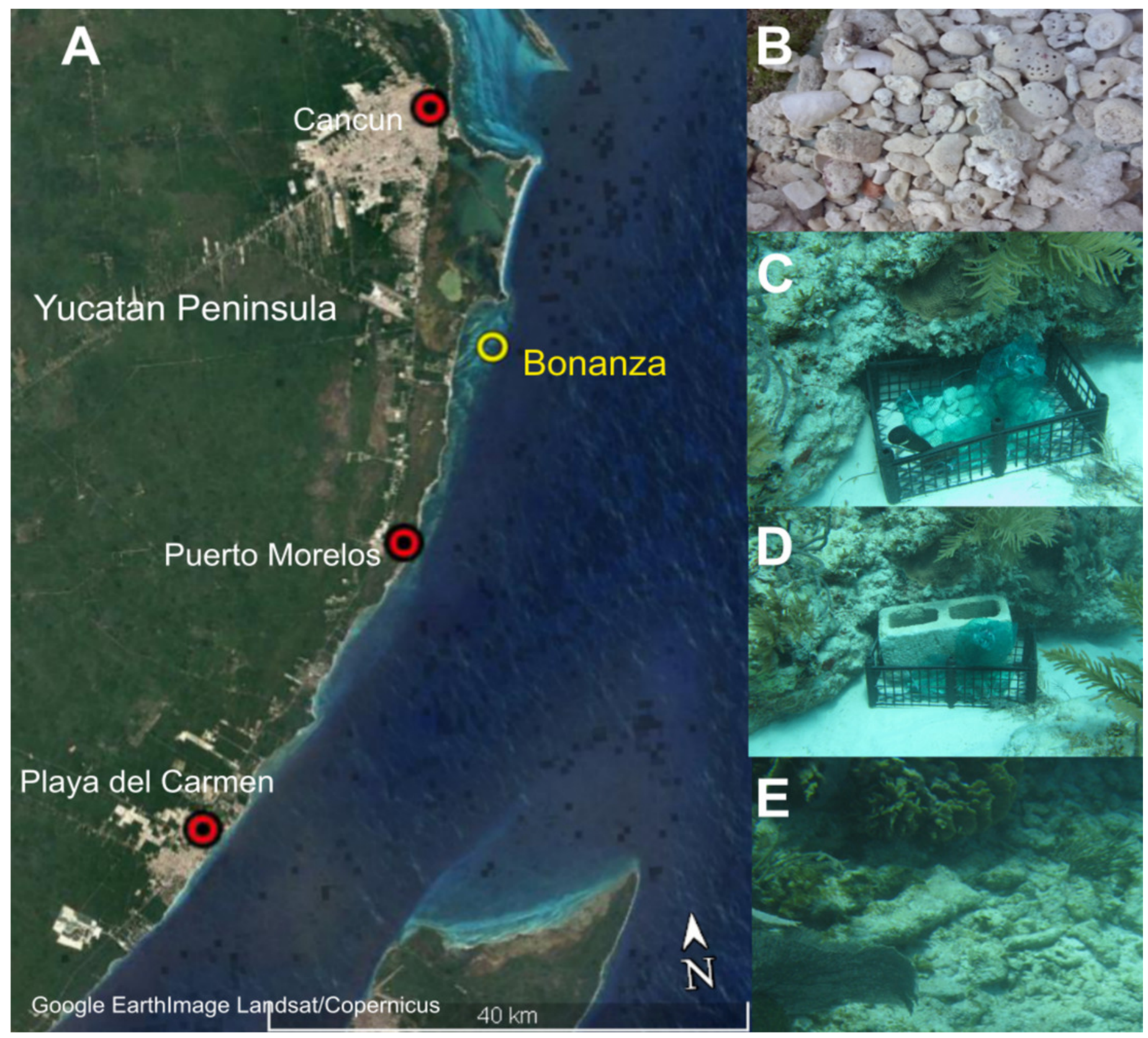




\section{Figure 2}

Diversity of cryptic crustacea by method

Sample-size-based rarefaction (solid lines) and extrapolation (dashed lines up to double the reference sample size) curves of motile cryptic crustacean diversity in artificial sampling units (ASU), in coral rubble collected in situ (CR), and in both methods combined (Total) based on three Hill's numbers: (A) $q=0$ species richness, $(B) q=1$ the exponential of Shannon's entropy index, and (C) $q=2$ the inverse of Simpson's concentration index. The 95\% confidence intervals (shaded areas) were obtained by bootstraping (300 replications).

Reference samples are denoted by solid markers.
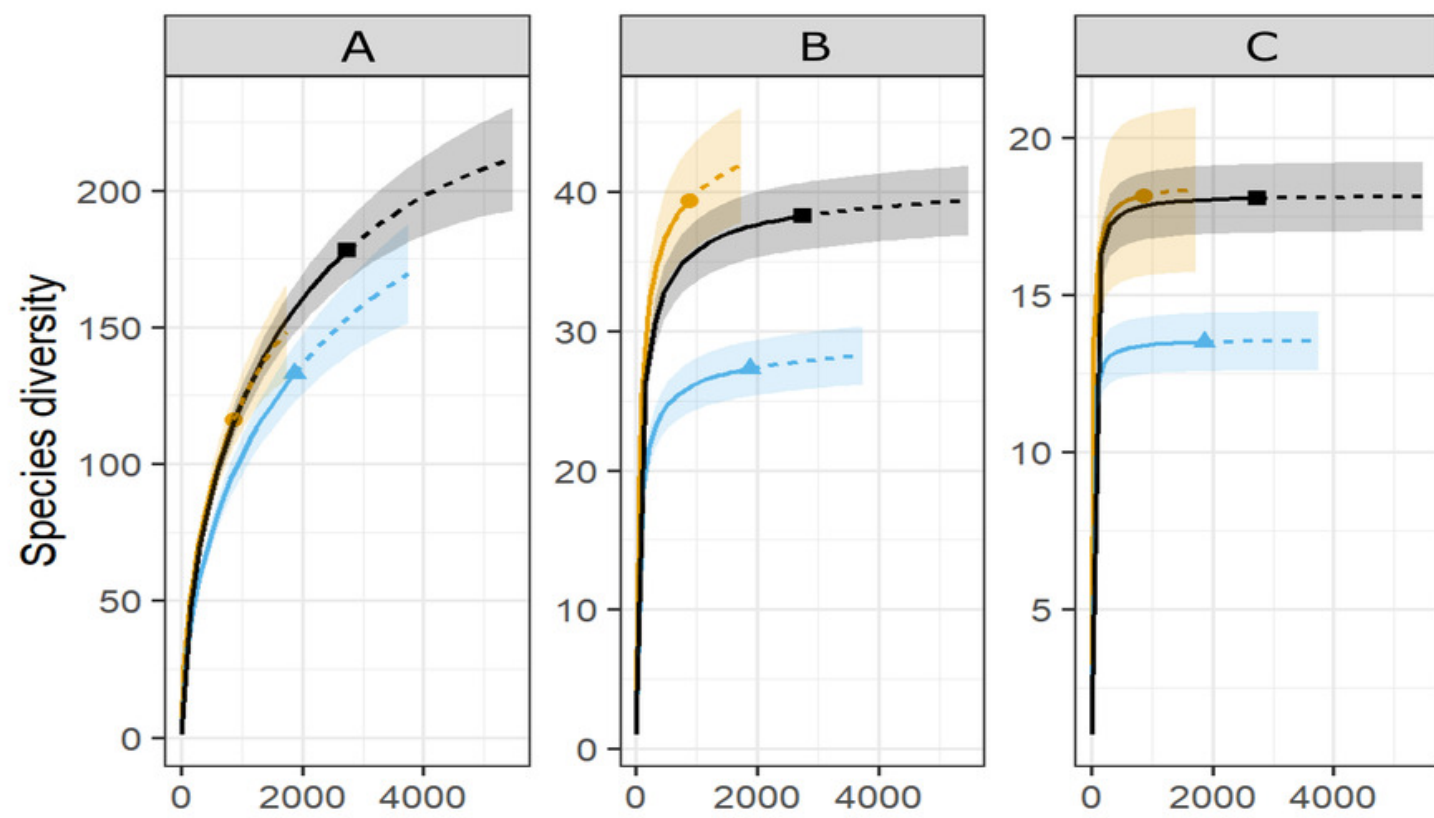

Method

- Interpolated

-.Extrapolated

Guides

- ASUs

CR

Total

Number of individuals 
Figure 3

Sample coverage by method

Coverage-based rarefaction (solid lines) and extrapolation curves (dashed lines up to double the reference sample size) based on species richness of the motile cryptic crustaceans in Bonanza reef site in 2013-2014. The 95\% confidence intervals (shaded regions) were obtained by bootstrapping (300 replications). Reference samples are denoted by solid markers.

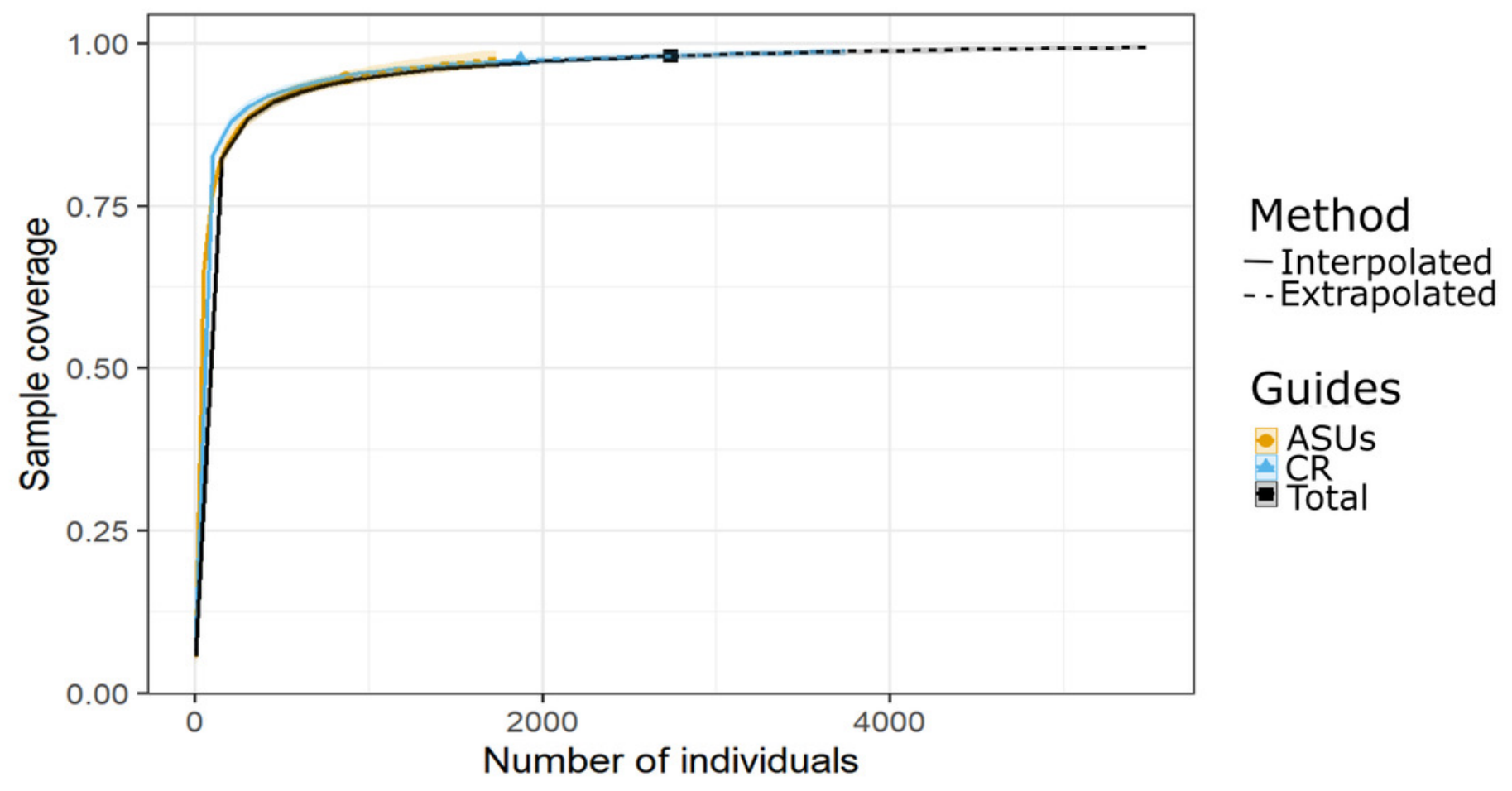




\section{Figure 4}

Non-metrical multidimensional scaling (nMDS) ordination plot

Non-metrical multidimensional scaling (nMDS) ordination plot based on Bray-Curtis

similarities of motile cryptofauna communities between artificial sampling units (ASU) and coral gravel collected in situ (CG). Letters A to D correspond to sampling periods: A) May 2013, B) August 2013, C) November of 2013, and D) January 2014.

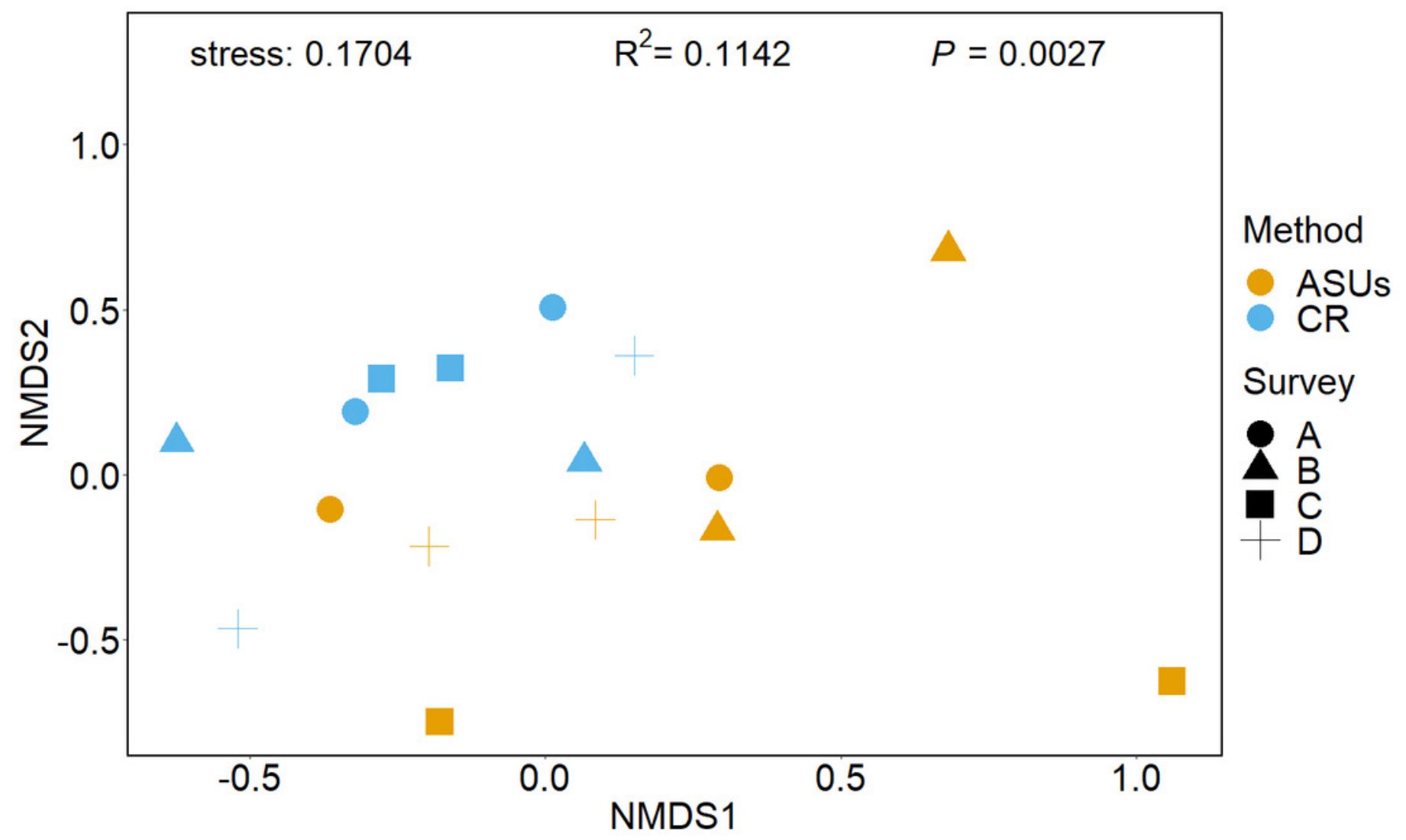




\section{Figure 5}

Ecological Importance Value Index

Ecological Importance Value Index of cryptic Crustacea species in artificial sampling units (ASUs) and in coral rubble collected in situ from Bonanza reef site in 2013-2014. The index is based on the relative abundance and frequency of each species with respect to the assemblage on each substrate. Only species with relative importance above $2 \%$ on either of the substrates are shown.

\section{ASUs Coral rubble}






\section{Table $\mathbf{1}$ (on next page)}

Number of families, species, and individuals of five Crustacea orders

Number of families $(\mathrm{F})$, species $(\mathrm{S})$ and individuals $(\mathrm{N})$ of five orders of Crustacea retrieved from artificial sampling units (ASUs) and from coral rubble collected in situ in the Bonanza reef unit of the Puerto Morelos Reef National Park in 2013-2014. 
1

2

\begin{tabular}{|c|c|c|c|c|c|c|c|c|c|c|}
\hline \multirow[t]{2}{*}{ Order } & \multicolumn{3}{|c|}{ ASUs } & \multicolumn{3}{|c|}{ Coral Rubble } & \multicolumn{3}{|c|}{ Total } & \multirow[t]{2}{*}{ Species shared } \\
\hline & $\mathbf{F}$ & $\mathbf{S}$ & $\mathbf{N}$ & $\mathbf{F}$ & $\mathbf{S}$ & $\mathbf{N}$ & $\mathbf{F}$ & $\mathbf{S}$ & $\mathbf{N}$ & \\
\hline Amphipoda & 17 & 25 & 159 & 15 & 29 & 195 & 19 & 39 & 354 & 15 \\
\hline Cumacea & 3 & 4 & 11 & 3 & 14 & 21 & 3 & 16 & 32 & 2 \\
\hline Isopoda & 10 & 29 & 267 & 11 & 39 & 438 & 12 & 48 & 705 & 20 \\
\hline Tanaidacea & 7 & 11 & 244 & 9 & 17 & 1140 & 9 & 18 & 1,384 & 10 \\
\hline Decapoda & 13 & 47 & 187 & 9 & 34 & 78 & 15 & 57 & 265 & 24 \\
\hline Total & 50 & 116 & 868 & 47 & 133 & 1,872 & 58 & 178 & 2,740 & 71 \\
\hline
\end{tabular}

3

4 